\title{
IMPACTO DA COVID-19 NAS EXPORTAÇÕES DAS PRINCIPAIS COMMODITIES BRASILEIRAS'
}

José Aroudo Mota²

\section{SINOPSE}

Diante das incertezas e oscilaçóes no mercado de commodities até 2019, surgiu, a partir de fevereiro de 2020, um novo ator de compressão do comércio internacional: a Covid-19 e seus impactos nas economias globais. Por um lado, alguns dos impactos negativos da pandemia da Covid-19 no produto interno bruto (PIB) dos países que têm laços comerciais com o Brasil já são mensuráveis. Por outro lado, o comércio exterior brasileiro tem demonstrado resiliência, especialmente o setor extrativo mineral e as commodities agrícolas. Este artigo analisa o comportamento do comércio exterior brasileiro no período de 2019 e 2020, enfatizando as principais commodities negociadas no mercado internacional.

Palavras-chave: comércio exterior; balança comercial; setor extrativo mineral; commodities agrícolas.

\section{INTRODUÇÃO}

A pandemia da Covid-19 produziu desaceleração econômica em nível global numa magnitude sem precedentes na história recente. A fim de minimizar esses impactos, os governos injetaram em suas economias um montante significativo de recursos financeiros em 2020, de modo a amortecer em parte o choque da pandemia e viabilizar uma retomada mais rápida da atividade produtiva.

Por seu turno, o Brasil continuou em busca da expansão de negócios, mesmo com as adversidades internacionais decorrentes da pandemia. Neste cenário, os negócios com as commodities minerais destacaram-se, especialmente pela resiliência da economia chinesa ao longo do ano, que manteve elevada sua demanda por insumos minerais e ampliou os seus negócios com o Brasil.

O objetivo deste artigo é avaliar os impactos e as perspectivas da crise gerada pela pandemia sobre as exportaçóes brasileiras de commodities minerais. Para tanto, a análise se concentra na recuperação econômica da China ao longo de 2020, uma vez que este constitui o principal mercado para os produtos minerais brasileiros, bem como na avaliação da retomada das economias centrais, em especial a dos Estados Unidos, após a definição da disputa presidencial em novembro.

\section{MATERIAL DA PESQUISA}

Os dados de comércio exterior do Brasil são catalogados e administrados pelo Ministério da Economia (na Secretaria de Comércio Exterior) e divulgados on-line com a tempestividade que o tema exige. Deste modo, as contas do setor extrativo, assim como as commodities agrícolas foram agrupadas e contabilizadas conforme descritas na tabela 1 .

1. DOI: http://dx.doi.org/10.38116/radar65art5

2. Pesquisador do Subprograma de Pesquisa para o Desenvolvimento Nacional (PNPD) na Diretoria de Estudos e Políticas Setoriais de Inovação e Infraestrutura (Diset) do Ipea. E-mail: <jamota2014@gmail.com>. 


\section{RESULTADOS}

Mesmo diante do retrocesso econômico que desestruturou a economia internacional em decorrência da Covid-19, o faturamento do Brasil com as exportações, ${ }^{3}$ no total de US\$209.878,4 milhóes (tabela 1), apresentou uma queda de 6,9\% em 2020 em relação a 2019; as importaçóes, no montante de US\$ 158.937,3 milhóes, caíram $10,4 \%$ no mesmo período.

Em 2020, os principais destinos das exportaçôes brasileiras foram: em primeiro lugar, a China, com total exportado de US\$ 67,8 bilhóes, correspondendo a 32,3\% das exportaçóes, e variação positiva de 7\% em relação a 2019, enquanto as importaçóes totalizaram US\$34,0 bilhóes, correspondendo a 23,3\% do total importado, e retração de 3,5\% em relação a 2019; em seguida, os Estados Unidos, com total exportado de US\$21,5 bilhões, correspondendo a 10,2\% das exportaçóes, e variação negativa de $27,7 \%$ em relação a 2019 , enquanto as importaçóes totalizaram US\$24,1 bilhões, correspondendo a 16,5\% do total importado, e retração de 19,8\% em relação a 2019. A pauta exportadora do Brasil em 2020 foi concentrada nos estados de Sáo Paulo (com participação de 20,4\%), Minas Gerais (com 12,6\%), Rio de Janeiro (com 11,0\%) e Pará (com 9,9\%), os quais foram responsáveis por $53,9 \%$ do total exportado.

Diante da conjuntura econômica nacional, decorrente dos efeitos de externalidades negativas gerados pela Covid-19, o impacto nas perdas das exportaçóes de commodities minerais foi sendo minimizado a partir da recuperação da economia internacional. O mês de março de 2020 foi marcado por um descompasso internacional caracterizado pelo início do retorno da atividade econômica na China, por um lado, e pelo agravamento da pandemia nos demais países, por outro lado. No Brasil, várias medidas de distanciamento social com o objetivo de conter a contaminação e preparar o sistema de saúde nacional para tratar os doentes foram iniciadas em todo o país. A partir de então, ao passo que a atividade econômica doméstica sofria com as medidas de contenção da pandemia, as exportaçóes brasileiras ganhavam impulso em decorrência da demanda proporcionada por grandes investimentos em infraestrutura realizados pela China. Por isso, chama atenção a declaraçáo do professor George Yip de que:

A China está se recuperando mais rapidamente do coronavírus do que o resto do mundo, o que significa que sua economia avançará e fortalecerá sua posição nas negociaçóes comerciais com os Estados Unidos. Enquanto isso, a queda no valor de mercado das empresas britânicas tornará mais fácil para as empresas chinesas, que são menos dependentes do mercado de açôes, fazer a aquisição de empresas ocidentais (WILSON, 2020, tradução nossa).

Os ganhos e as perdas aparentes decorrentes da pandemia da Covid-19 estão demonstrados na tabela 1. Ao contrário da tendência geral da pauta exportadora brasileira, as commodities do setor extrativo mineral aumentaram o seu faturamento em 14,5\% em 2020 contra 2019, correspondendo a um ganho de quase US\$ 4,3 bilhóes e pouco mais de 1,8 milhão de toneladas exportadas a mais.

O minério de ferro ${ }^{4}$ e seus concentrados se destacam, mesmo com uma perda aparente de comércio de 245,0 mil toneladas, mas com um ganho substancial no total exportado de pouco mais de US\$ 3 bilhóes, resultado influenciado pela alta nos preços por tonelada. Os principais compradores foram a China, com $71,8 \%$ do total exportado, e a Malásia, num distante segundo lugar, com 6,6\% de participação.

O ouro não monetário, com aumento de 34,0\% nas exportaçóes no mesmo período, apresentou um ganho de US\$ 1,2 bilhão, correspondendo a 5,0 toneladas adicionais em 2020. Seus principais compradores foram o Canadá (com 38,2\% de participação), a Suíça (com 21,0\%), o Reino Unido (com 13,1\%), os Emirados Árabes (com 7,8\%) e a Itália (com 6,1\%, aproximadamente). O preço médio de exportação do ouro aumentou 13,2\% em 2020 com base em 2019, sendo negociado a US\$ 44,4 mil FOB $/ \mathrm{kg}$.

3. Todos os valores estão expressos em dólares americanos.

4. 0 minério de ferro representou, em 2020, 12,3\% das exportações do Brasil; e ocupou o segundo lugar no ranking das exportações totais e o primeiro no ranking da indústria extrativa mineral. Os preços de sua exportação em dólares free on board por quilo (US\$ FOB/kg) aumentaram 33,3\% em 2020 com base em 2019. 
O grupo da soja e seus derivados, por sua vez, obteve, em 2020, um aumento de 9,5\% em relação a 2019, equivalente a um ganho de US\$ 2,5 bilhóes e de 8,9 milhóes de toneladas no volume exportado no mesmo período. Os diversos tipos de carne também obtiveram ganhos em suas exportaçóes no mesmo período, atingindo US\$ 550,8 milhóes e 352,2 mil toneladas no volume exportado. Entretanto, o milho apresentou um desempenho negativo, com US\$ 1,4 bilhão de perda de exportação em relação a 2019, referentes a 8,3 milhóes de toneladas.

Este grupo de produtos (composto por commodities da indústria extrativa mineral, óleos brutos de petróleo, soja e derivados, diversos tipos de carne e milho) respondeu por 49,6\% das exportaçóes de 2020 e 45,6\% das de 2019; no conjunto, apresentou um ganho, em 2020, no valor de US\$1,3 bilhão.

TABELA 1

Ganhos e perdas nas exportações brasileiras de commodities (2019 e 2020)

\begin{tabular}{|c|c|c|c|c|}
\hline \multirow{2}{*}{ Principais produtos exportados } & \multicolumn{2}{|c|}{ Exportações (US\$ milhões) } & \multicolumn{2}{|c|}{ Ganho ou perda } \\
\hline & 2019 & 2020 & US\$ milhões & Toneladas \\
\hline 1. Minério de ferro e seus concentrados & $22.680,9$ & $25.780,5$ & $3.099,6$ & $-245,0 \mathrm{mil}$ \\
\hline 2. Minério de cobre e seus concentrados & $2.325,7$ & $2.408,9$ & 83,2 & $-13,3 \mathrm{mil}$ \\
\hline 3. Ouro, uso não monetário & $3.658,4$ & $4.903,4$ & $1.245,0$ & 5,043 \\
\hline 4. Minério de manganês & 490,1 & 346,6 & $-143,5$ & $-712,9 \mathrm{mil}$ \\
\hline 5. Minério de alumínio & 258,3 & 169,5 & $-88,8$ & $2.580,0 \mathrm{mil}$ \\
\hline 6. Demais minérios & 87,2 & 178,8 & 91,6 & $220,3 \mathrm{mil}$ \\
\hline 7. Indústria extrativa mineral $(1+\ldots+6)$ & $29.500,6$ & $33.787,7$ & $4.287,1$ & $1.829,1 \mathrm{mil}$ \\
\hline 8. Óleos brutos de petróleo & $24.199,5$ & $19.613,8$ & $-4.585,7$ & $-9.928,7 \mathrm{mil}$ \\
\hline 9. Indústria extrativa $(7+8)$ & $53.700,1$ & $53.401,5$ & $-298,6$ & $\ldots$ \\
\hline 10. Soja e seus derivados 1 & $26.773,5$ & $29.327,6$ & $2.554,1$ & $8.968,9 \mathrm{mil}$ \\
\hline 11. Diversos tipos de carnes2 & $15.015,3$ & $15.566,1$ & 550,8 & $352,2 \mathrm{mil}$ \\
\hline 12. Milho & $7.212,2$ & $5.786,1$ & $-1.426,1$ & $-8.323,7 \mathrm{mil}$ \\
\hline Subtotal $(9+10+11+12)$ & $102.701,1$ & $104.081,3$ & $1.380,2$ & $\ldots$ \\
\hline Demais produtos & $122.682,4$ & $105.797,1$ & $-16.885,3$ & $\ldots$ \\
\hline Total & $225.383,5$ & $209.878,4$ & $-15.505,1$ & \\
\hline
\end{tabular}

Fonte: Comex Stat (estatísticas de comércio exterior brasileiro). Disponível em <http://comexstat.mdic.gov.br/pt/home>. Acesso em: 14 fev. 2021.

Elaboração do autor.

Notas: ' Soja mesmo triturada + farelo e resíduos da extração de óleo de soja.

${ }^{2} \mathrm{~A}$ conta inclui carne de bovino, equino, caprino, frango, pato, ganso e peru congelada, fresca ou refrigerada (as carnes de frango, pato, ganso e peru incluem os miúdos) + carnes salgadas incluídas as de frango + tripas e buchos de animais, frescos, salgados ou secos.

\section{CONSIDERAÇÕES FINAIS}

Os impactos da Covid-19 nas exportaçóes brasileiras foram marginais, quando comparados com as demais economias mundiais, em virtude da forte demanda chinesa. O saldo comercial com a China, em 2020, foi superavitário em US\$ 33,7 bilhóes e a corrente de comércio atingiu US\$101,8 bilhóes; entretanto, com os Estados Unidos, o saldo de comércio apresentou um deficit de US\$2,6 bilhóes e uma corrente de comércio de US\$ 45,6 bilhóes.

No final de fevereiro de 2021, após amplo esforço bipartidário, o Congresso dos Estados Unidos aprovou um pacote de estímulos de US\$ 1,9 trilhão, destinado a mitigar os efeitos econômicos da pandemia da Covid-19 e acelerar a retomada do emprego e da produção industrial. Embora seus efeitos ainda estejam por ser sentidos nos próximos meses, o anúncio do pacote já precipitou uma melhoria nas expectativas quanto ao desempenho da economia global. Uma vez que a China é bastante impactada pelo desempenho da economia americana, essa injeção significativa de recursos também deve acelerar a recuperaçáo econômica do país asiático, com impactos indiretos positivos para a exportação de commodities minerais do Brasil. 
Certamente, dois pontos devem chamar atenção dos gestores públicos brasileiros. $\mathrm{O}$ primeiro se refere à elevada dependência de produtos primários em nossa pauta exportadora; e o segundo, à excessiva concentração em poucos parceiros comerciais. $\mathrm{O}$ momento é de cautela, pois o país precisa, primeiro, sair da pandemia para permitir um crescimento econômico duradouro e, num segundo momento, definir políticas públicas de inovação e tecnologia para agregar valor aos produtos exportados pelo Brasil.

\section{REFERÊNCIA}

WILSON, J. The economic impact of coronavirus: analysis from Imperial experts. Imperial College London News, 13 May 2020. Disponível em: <https://bit.ly/3tyP5zM>. Acesso em: 16 maio 2020.

\section{BIBLIOGRAFIA COMPLEMENTAR}

KRUGMAN, P. Republicans, businesspeople, and other bad economists. The New York Times, New York, 25 Aug. 2020. THE ECONOMIST. Economic \& financial indicators. The Economist, London, v. 435, n. 9194, p. 80, 16 May 2020. 